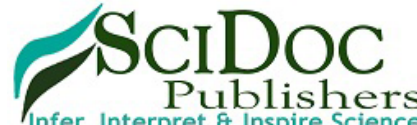

\author{
International Journal of Dentistry and Oral Science (IJDOS) \\ ISSN: 2377-8075
}

\title{
Comparative Evaluation Of Second Generation Platelet Concentrates On Fibroblast Cell Viability And Migration
}

Research Article

Swapna Chekurthi ${ }^{1^{*}}$, Anupama Tadepalli ${ }^{2}$, Harinath Parthasarathy ${ }^{3}$

${ }^{1}$ Post Graduate Student, Department Of Periodontology, SRM Dental College, Chennai, Tamilnadu, India.

${ }^{2}$ Reader, SRM Dental College, Chennai, Tamilnadu, India.

${ }^{3}$ Professor, SRM Dental College, Chennai, Tamilnadu, India.

Abstract

Objective: The aim of this study was to compare the effect of L-PRF, A-PRF, A-PRF+ on fibroblasts by evaluating the viability and migration of cells.

Methods: Peripheral blood samples were collected from 3 healthy volunteers ( 3 from each individual for L-PRF, A-PRF and A-PRF+). Following respective centrifugation protocols L-PRF (2700 rpm for $12 \mathrm{~min})$, A-PRF (1500 rpm for 14min), A$\mathrm{PRF}+(1500 \mathrm{rpm}$ for $8 \mathrm{~min})$ membranes were obtained. 3T3 fibroblast cell lines were treated with each membrane and cell viability was assessed by MTT assay. Fluorescent images were captured and quantified with an inverted fluorescent microscope. Cell migration was assessed by scratch wound healing assay at intervals of $0,24,48$ and $72 \mathrm{hrs}$. Wound closure was analysed under the inverted microscope.

Results: At $24 \mathrm{hrs}$, no statistically significant differences were noted with regard to cell viability among A-PRF, A-PRF+ and L-PRF groups $(98.33 \pm 4 \%, 99.18 \pm 4 \%$ and $99 \pm 2 \%, \mathrm{p}>0.05)$. Within the groups there were significant differences in cell migration, from 0 hrs to 24, $(p<0.05), 24$ to $48 \mathrm{hrs}(\mathrm{p}<0.001)$ and 48 to $72 \mathrm{hrs}(\mathrm{p}<0.01)$. Significant differences were also noted between L-PRF and A-PRF at all time intervals while closing the cell free scratch area.

Conclusion: The results from the present study demonstrates higher cell viability indicating excellent biocompatibility of all the platelet rich membranes on fibroblasts and L-PRF showing higher fibroblast migration over the advanced fibrins (A-PRF and $\mathrm{A}-\mathrm{PRF}+$ ) at early time intervals indicating rapid degranulation. Further studies with increased sample size over a longer evaluation period are required to confirm the results.

Keywords: Centrifugation; Cell Survival; Cell Migration; Fibroblasts; Platelet Rich Fibrin; Wound Healing.

\section{Introduction}

Periodontal regeneration is a complex biological mechanism in which multiple cellular events occur concurrently leading to repair or regeneration and its unique structure makes regeneration more difficult as it involves the interaction between both hard and soft tissues comprising of gingival connective tissue, cementum, periodontal ligament and bone [1]. Wound healing process is regulated and stimulated by various biological mediators known as growth factors. Platelets are the initial cells involved in the wound healing process. They instigate the coagulation cascade, establish fibrin meshwork which acts as a provisional matrix maintaining the space for regeneration. Platelets on activation, release various bioactive molecules like platelet derived growth factor (PDGF), fibroblast growth factor(FGF), vascular endothelial growth factor (VEGF), epidermal growth factor (EGF), transforming growth factor (TGF), insulin like growth factor (IGF), cytokines, and adhesive proteins stimulating various inflammatory cells to populate the area and also regulate their growth factor release. These bioactive molecules trigger signal transduction, leading to gene transcription, promoting cellular functions like proliferation, differentiation, matrix remodeling, and angiogenesis thereby setting the pace for the wound healing process. Platelets concentrates aims at extracting all the potential elements present in the collected blood sample and providing supra-physiological concentration at the surgical site with a goal to accelerate the healing process and regeneration of lost tissues $[2,3]$. The second generation platelet concentrates are formed by natural polymerization during centrifuga-

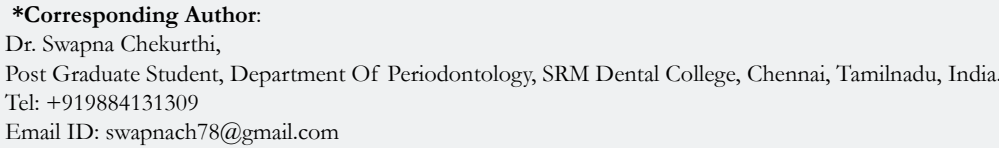

Received: February 22, 2021

Accepted: March 25, 202

Published: April 03, 2021

Citation: Swapna Chekurthi, Anupama Tadepalli, Harinath Parthasarathy. Comparative Evaluation Of Second Generation Platelet Concentrates On Fibroblast Cell Viability And Migration. Int J Dentistry Oral Sci. 2021;08(04):2176-2181. doi: http://dx.doi.org/10.19070/2377-8075-21000430

Copyright: Swapna Chekurthi 2021 . This is an open-access article distributed under the terms of the Creative Commons Attribution License, which permits unrestricted use, distribution and reproduction in any medium, provided the original author and source are credited. 
tion, that resulted in a three-dimensional fibrin architecture with equilateral junctions that mimic the extracellular matrix structure, offering flexibility and elasticity. These linked junctions facilitate the migration of fibroblasts and endothelial cells, circulating stem cells, enmeshment of cytokines, and their continuous release over a period of time, providing an atmosphere for cells to function optimally $[4,5]$. However, due to high centrifugation force $(3000$ rpm for $10 \mathrm{~min}$ at $708 \mathrm{G}$ ) in L-PRF, cell population shift to the bottom of the tubes, resulting in less number of desired cells in the procured PRF clot. The innovation of Low speed centrifugation concept (LSCC) by Choukroun et al 2014 led to the evolution of Advanced platelet rich fibrins (A-PRF, A-PRF+) [6]. A-PRF with a modified preparation protocol of $1500 \mathrm{rpm}$ for $14 \mathrm{~min}$ at $200 \mathrm{G}$, exhibited porous fibrin structure with larger inter fibrinous space incorporating quantitatively more platelets and inflammatory cells, evenly distributed all through the matrix releasing significantly increased growth factor proteins like over a period of time. A-PRF was found to contain increased VEGF (vascular endothelial growth factor) responsible for neoangiogenesis, monocytes as a source for BMP's (bone morphogenic proteins) and fibronectin for extracellular matrix formation [7-9]. To further improve the functional integrity and handling properties of A-PRF, centrifugation protocol was modified again which resulted in formation of an improved clot termed Advanced PRF plus (A-PRF+). A$\mathrm{PRF}+$ barely needs to be processed as it lies separated from the red cell fraction. EL Bagdadi et al., in 2017 when he compared the growth factor release from PRF, A-PRF and A-PRF+, A-PRF+ showed significantly higher release [10]. Fibroblasts are the major cells of connective tissue and play a crucial role in the proliferative and remodelling phases of wound healing. Fibroblasts migrate, proliferate, and synthesize large amounts of collagen and other extracellular matrix. They are extremely sensitive to any changes in their surrounding matrix, growth factors or cytokines. They have the ability to migrate in the direction of chemotaxis. This property of fibroblast migration is responsible for tissue regeneration and repair during wound healing [11].

Various clinical applications of these platelet formulations in intrabony defects managements, sinus lift procedures, osteonecrosis, implant surgeries, ridge preservation, ridge augmentation and treatment of maxillary cysts have shown the promising effects on hard and soft tissue regeneration. Clinical studies to determine the superiority/equivalence of A-PRF to L-PRF is still in infancy level hence more invitro studies are required to establish their efficacy on various cells involved in soft and hard tissue regeneration. Since there was sparse literature evaluating the effect of novel PRF preparations on the fibroblasts, this research aims to investigate the influence of L-PRF, A-PRF and A-PRF+ on fibroblast viability and their migration.

\section{Materials and Methods}

\section{Blood collection}

Systemically healthy adults with platelet counts in normal range were explained about the purpose of the research and informed consent was obtained from voluntary participants. Peripheral blood samples were collected from three eligible donors in sterile $12 \mathrm{ml}$ vaccum PRF tubes ( $10 \mathrm{ml}$ for each protocol).

\section{Preparation of platelet rich fibrins}

The procured blood samples collected were centrifuged $2700 \mathrm{rpm}$ for $12 \mathrm{~min}$ at $708 \mathrm{~g}$ force for LPRF, $1500 \mathrm{rpm}$ for $14 \mathrm{~min}$ for A$\mathrm{PRF}$ and $1500 \mathrm{rpm}$ for $8 \mathrm{~min}$ for A-PRF + at $200 \mathrm{~g}$ force respectively in a preprogrammed centrifuge ( LD-C10). PRF clots were carefully retrieved and gently compressed to obtain membranes. (Fig-1: 1a,1b,1c)

\section{Cell culture}

The primary mouse embryonic fibroblast cells are cultured with 3T3 protocol. Fibroblasts are transferred $(\mathrm{T})$ every 3 rd day till the cell density reached $3 \times 105$ cells for $20 \mathrm{~cm}^{2}$. The obtained membranes were immediately tested for cell viability and cell migration on the 3T3 fibroblast cell line.

\section{Evaluation of cell viability by MTT assay}

The cytotoxicity effect was tested against normal fibroblast cell line (3T3) by MTT (3-(4,5-dimethylthiazol-2-yl)-2,5-diphenyltetrazolium bromide assay (Mossman, 1983) [12]. The cells were seeded in 96-well microplates $\left(1 \times 106\right.$ cells/well) and incubated at $37^{\circ} \mathrm{C}$ for $24 \mathrm{~h}$ in $5 \% \mathrm{CO}_{2}$ incubator and allowed to grow $80 \%$ confluence. Then the medium was replaced and the cells were treated with LPRF, A-PRF, A-PRF+ and incubated for 24hr. The cells were then washed with phosphate-buffer saline (PBS, pH- 7.4) and $20 \mu \mathrm{L}$ of (MTT) solution ( $5 \mathrm{mg} / \mathrm{mL}$ in PBS) was added to each well. The plates were then placed at $37^{\circ} \mathrm{C}$ in the dark for additional 1-3hrs. The formazan crystals were dissolved in $100 \mu \mathrm{L}$ DMSO (dimethy sulphoxide) and the absorbance was read spectrometrically at 570 $\mathrm{nm}$. The morphological changes of untreated (control) and the treated cells were observed under a bright field microscope after $24 \mathrm{hr}$ and photographed Fig-2: (2a,2b,2c,2d). Percentage of cell viability was calculated using the formula,

Cell viability $(\%)=(\mathrm{OD}$ of sample $/ \mathrm{OD}$ of cell control $) \mathrm{X} 100$.

Assessment of cell migration

Figure 1. 1a: The centrifuge used for obtaining the membranes for this study is LD-C10 Platelet rich fibrin membrane obtained are shown in 1band $1 \mathrm{c}$.

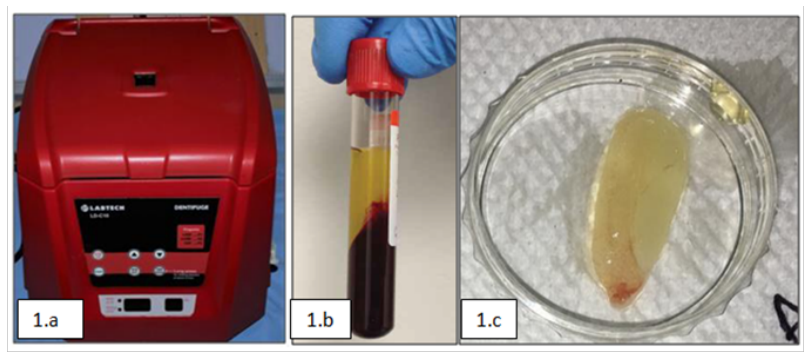


In vitro scratch wound closure assay was used for the assessment of cell migration. The 3 T 3 cells were seeded in 6 -well plates $(8 \times$ $10^{5}$ cells/well) and grown until confluence of $90 \%$ was reached, in the optimum culture conditions. In the middle of the cell monolayer, a scratch was made by a P10 pipette tip, to mimic a wound and cell debris was removed by washing with a fresh medium Fig3: $(3 a, 3 b)$. The wound was exposed to sample and incubated at $37^{\circ} \mathrm{C}$ in a humidified atmosphere of $5 \% \mathrm{CO}_{2}$. The negative control cells were maintained without any treatment. Scratch wound closure was analyzed under the inverted microscope (Magnus INVI, Noida), and four digital images were taken at $0 \mathrm{hr}(\mathrm{t} 0)$, $24 \mathrm{hrs}(\mathrm{t} 1)$, 48hrs (t2) and $72 \mathrm{hrs}$ (t3) (static imaging) (Fig-4). The closure of the scratch was quantified by measuring the difference between the wound width at $\mathrm{t} 0$ and $\mathrm{t} 1 / \mathrm{t} 2 / \mathrm{t} 3$, using the Image $\mathrm{J}$ processing software [http://rsbweb.nih.gov/ij/]. Scratch Closure Rate (SCR) was calculated as described by Felice et al using the following formula:

$\mathrm{SCR}=[(\mathrm{t} 0-\mathrm{t} 1) / \mathrm{t} 0] \times 100$

$(\mathrm{t} 0=$ scratch area at time $0 \mathrm{hr} ; \mathrm{t} 1=$ scratch area at $24 \mathrm{hrs})$

\section{Statistical Analysis}

Each step was repeated in triplicate and Statistical analysis was performed using Statistical Package for Social Science software (SPSS, version 17) through one way ANOVA. Pairwise comparisons were done using Tukey's test. The level of significance was set at $\mathrm{p}<0.05$.

Results
The mean cell viability noted was $98.33 \pm 4 \%, 99.18 \pm 4 \%, 99$ $\pm 2 \%$ in A-PRF, A-PRF+ and L-PRF respectively. There was no statistical significant difference ( $p>0.05$ ) among A-PRF, A-PRF+ and L-PRF groups with respect to cell viability (Fig-5). 100\% cell viability was noted in negative control and there was no significant difference in cell viability for the negative control group and the groups treated with membranes.

As shown in Fig-6 the scratch wound closure depicts the migration of fibroblasts at different time points at $0 \mathrm{hrs}, 24 \mathrm{hrs}, 48 \mathrm{hrs}$ and 72 hrs. At 24 and 48 hrs there was a statistical significant difference between A-PRF and A-PRF+ groups $(\mathrm{P}<0.05)$, but no significance difference between L-PRF and A-PRF+( $>>0.05)$. At $72 \mathrm{hrs}$ there was statistical significant cell migration noted in all the groups but a significantly higher migration in L-PRF group ( 96.15\%) compared to A-PRF $(76.94 \%)(\mathrm{p}<0.001)$ and A-PRF+ $(82.69 \%)(p<0.01) . A-P R F$ and A-PRF+ groups also displayed significant difference in the fibroblast cell migration $(\mathrm{p}<0.01)$. Within the groups there was a significant cell migration, closing the cell free scratch area from 0 hrs to 24 , $(\mathrm{p}<0.05), 24$ to $48 \mathrm{hrs}$ $(\mathrm{p}<0.001)$ and 48 to $72 \mathrm{hrs}(\mathrm{p}<0.01)$.

\section{Discussion}

Platelet concentrates have come a long way from their first introduction in 1954 by Kingsley, as PRP (platelet rich plasma) the first generation of thrombocyte concentrate to L-PRF (LeukocytePlatelet rich fibrin) the second generation of platelet concentrate (by Joseph Choukroun et al 2001). PRP is an autologous supersaturated platelet concentrate with almost 5 times to the platelets present in natural clot [3]. It has numerous applications in medical field which includes spinal fusion, aesthetic plastic surgery, heart bypass surgery, chronic soft tissue and skin ulcers etc and was later

Figure 2. The images of cells a) control -untreated cells b) treated with L-PRF c) treated with A-PRF d) treated with APRF+ under bright field microscope after 24 hrs.
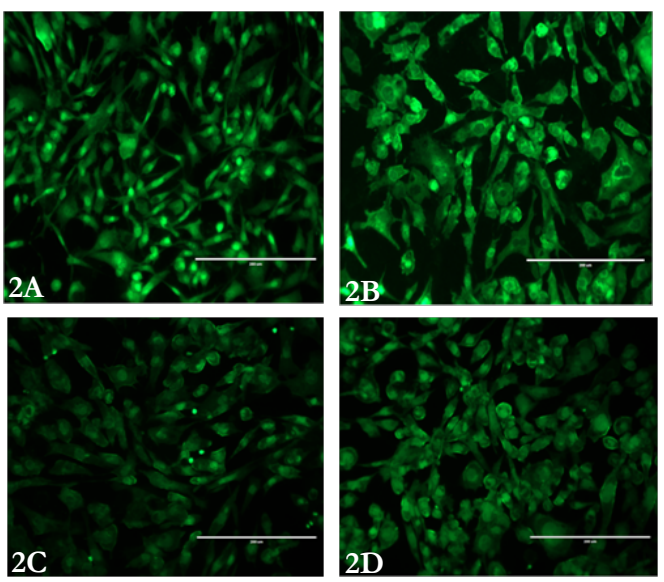

Figure 3. a) $90 \%$ confluence b) cell migration at t 0 .

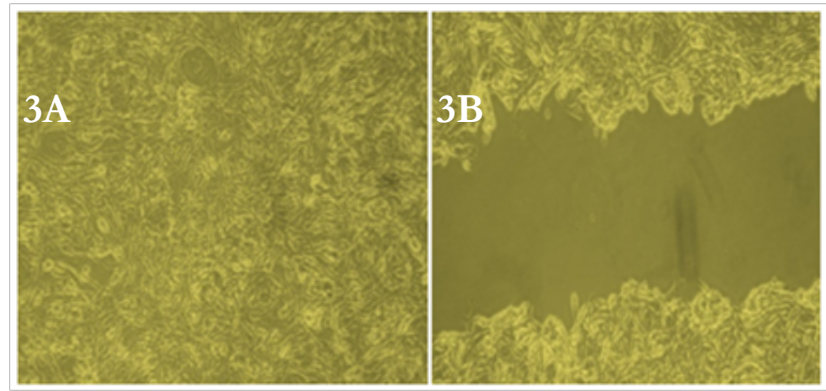


Figure 4. Shows cell migration at 24, 48 and $72 \mathrm{hrs}$ in L-PRF,A-PRF and A-PRF+ groups.

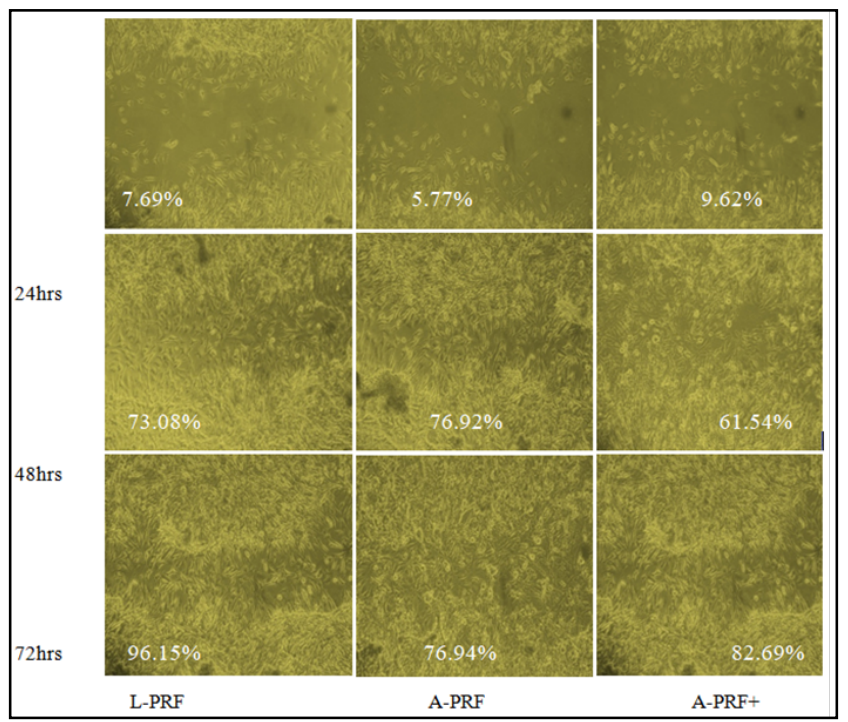

Figure 5. Plotted using the cell viability $(\%)$ at $\mathrm{Y}$-axis and concentration of the sample in $\mathrm{X}$-axis.

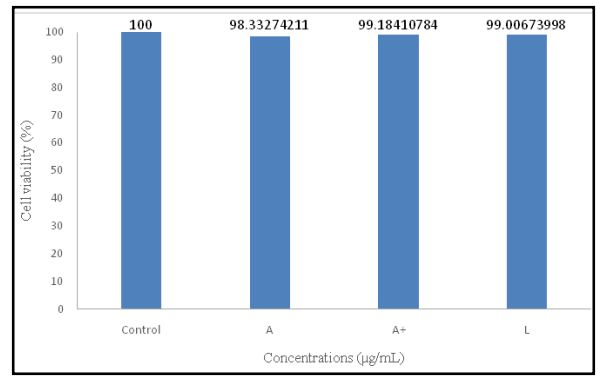

Figure 6. Plotted cell migration (\%) at $\mathrm{Y}$ axis and concentration of the sample at 24,48 and $72 \mathrm{hrs}$ on the $\mathrm{X}$-axis.

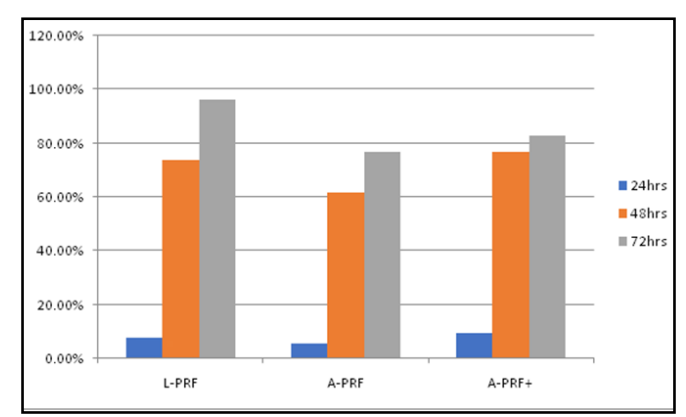

instituted into oral and maxillofacial surgery in 1997 by Whitman [13]. However, it had the drawbacks of use of external additive agents (bovine thrombin, calcium chloride), the known inhibitors of wound healing, with the possible risk of bleeding episodes, contamination and antibody development leading to coagulopathies $[14,15]$. The other limitations of PRP is its long preparation/centrifugation time, liquid nature and its early "burst" release of growth factors over a short period of time. PRF (Platelet Rich Fibrin) is considered as a big leap in platelet concentrates as it was based on the natural polymerization of the fibrin gel. The crux of PRF synthesis lies in its ability to accumulate platelets, leukocytes and the cytokines in a fibrin clot. Presence of growth factors (PDGF, TGF- $\beta$, VEGF, IGF EGF) and their gradual release from the PRF matrix are responsible for its healing potential [16]. In addition, entrapped leukocytes play important role in immune mechanism recruiting and directing various other cell types repopulating the wounded site, facilitating the repair and regeneration $[4,5]$. The use of these PRFs in various fields of dentistry is steadily increasing because of their $100 \%$ autologous nature, easy and less time consuming process. Due to the wide range of therapeutic applications, various researchers have been trying to enhance the growth factor release of conventional PRF by modifying the preparatory protocol.

In the Ghannati et al study cells were histologically quantified in L-PRF and it was found that most of the cells are prominent at the bottom of the fibrin clot in standard L-PRF which had high centrifugation speed (700G). Based on his findings it was thought that higher $G$-forces resulted in more of the leukocytes at the bottom of the tubes so by reducing the G-force and increasing the time has resulted in the formation of advanced platelet rich fibrin (A-PRF). Ghanati et al showed that low centrifugation speed resulted in platelets distributed all through the fibrin matrix with more of their number in distal part along with the presence of leukocytes. Higher presence of these cells in the advanced fibrins will help in recruiting more of the host macrophages to the surgical site and with their release of various growth factors might influence the both hard and soft tissue regeneration [6]. The objective of this study is to evaluate the effect of platelet rich membranes on the fibroblast viability and their migration. 
Masako Fujioka-Kobayashi et al demonstrated that the advanced fibrins (A-PRF and A-PRF+) showed increased release of growth factors (PDGF, TGF- $\beta 1, \mathrm{EGF}$ and IGF). Advanced formulations also exhibited increased proliferation and migration of gingival fibroblasts $(300 \%)$ than standard L-PRF and all the platelet formulations demonstrated excellent cell viability at $24 \mathrm{hrs}$ [8]. Similarly the present study showed L-PRF, A-PRF, and A-PRF+ with excellent cell viability suggesting biocompatibility. Bagdadi et al when evaluated the growth factor release (transforming growth factor beta-TGF- $\beta 1$, vascular endothelial growth factor-VEGF, and Epidermal growth factor- EGF) within the three PRF (platelet-rich-fibrin) matrices (PRF, A-PRF and A-PRF+) over 10 days, reported that accumulated release on day 10 was significantly higher in A-PRF+ compared with A-PRF and PRF and this studyaccentuated the fact that with a reduction of RCF (low speed centrifugation concept), growth factor release can be increased in leukocytes and platelets within the solid PRF matrices.10Whereas Meidyawati et al when evaluated lysate-PRF in inducing proliferation of fibroblast cells in endodontic regenerative therapy reported that both formulations exhibited similar ability as FBS $10 \%$ in inducing proliferation of fibroblasts [17]. Vahabi et al., reported a statistical significant increase in human gingival fibroblasts proliferation at $24 \mathrm{hrs}$ when treated with PRF indicating "proliferative burst" and further decrease in cell viability and proliferation after $24 \mathrm{hrs}$ upto $38 \%$ and $60 \%$ at 48 and $72 \mathrm{hrs}$ [18]. In the present study cell viability was assessed only at $24 \mathrm{hrs}$ and showed no significant difference among groups and all the PRF membranes demonstrated increased migration from 0 to 24,48 and 72 hrs.LPRF showed higher cell migration at all points. In the present study 3 volunteers participated and each volunteer contributed to all the three membranes ( L-PRF, A-PRF, and A-PRF+). Evidence from various studies suggest the existence of significant differences in relation to growth factor content (TGF- $\beta 1$, VEGF, platelet derived growth factor-PDGF, and basic fibroblast growth factor -bFGF) in individuals with similar platelet concentrations which explains the inter-individual variations [19]. Platelet concentrates have various growth factors with particularly diverse properties and effects. Platelet granules release angiogenic factors like VEGF and bFGF additionally angiostatic factors like endostatin and thrombospondin-1 each demonstrating confounding effects. So variations in the content of these proteins between individuals could have also influenced the outcome [20]. The mitogenic ability of platelet concentrate is just not confined to platelets and their growth factors even the biological membrane acting as a three dimensional scaffold with entrapped inflammatory cells and their sustained release of their growth factors could play a role in the present study which differed from most experimental studies which were done on platelet rich plasma and PRF supernatant. Dohan Ehrenfest et al showed a significant stimulatory and proliferative effect of PRF on human gingival fibroblasts at 3,7,14 and 21 days [21], similarly in the present study significant fibroblast migration was noted in all three groups at 24, 48 and $72 \mathrm{hr}$ with in vitro scratch wound healing assay an easy and economical method to assess the proliferation and migration of cells along the wound space artificially created.

Within the limitations of the study L-PRF showed significantly greater stimulatory effect on the fibroblasts at day all the three time points (24, 48 and $72 \mathrm{hrs}$ ) when compared to A-PRF and $\mathrm{A}-\mathrm{PRF}+$, this might be due to quantitatively increased leukocyte content and their biological effects of matrix metalloproteinases
8 and 9 and can also be attributed to the proliferative burst of L-PRF as suggested by Vahabi et al. Kobayashi et al stated that advanced platelet rich fibrins exhibit different release kinetics, APRF exhibited higher growth factor release at 3rd day and 10th day period when compared to L-PRF. Limitations of our study include the small sample size and evaluating the cellular viability and migration for a shorter period of time (24hrs and 24,48 and 72 hrs respectively), instead evaluation for a longer period $>3$ days could have provided different outcomes.

\section{Conclusion}

The results from the present study demonstrates higher cell viability indicating excellent biocompatibility of all the platelet rich membranes on fibroblasts and L-PRF showing higher fibroblast migration over the advanced fibrins (A-PRF and A-PRF+) at early time intervals indicating rapid degranulation. Further studies with increased sample size over a longer evaluation period are required to confirm the results.

\section{Acknowledgement}

Avanz Bio Pvt. Ltd. (ISO 9001:2015 Cert No:762545)

Mr. Porchelvan statistician.

I extended my sincere thanks for their invaluable support.

\section{References}

[1]. Polimeni G, Xiropaidis AV, Wikesjö UM. Biology and principles of periodontal wound healing/regeneration. Periodontol 2000. 2006;41:30-47. Pubmed PMID: 16686925.

[2]. Walsh TG, Metharom P, Berndt MC.The functional role of platelets in the regulation ofangiogenesis. Platelets2015.;26(3):199-211.Pubmed PMID: 24832135.

[3]. Agrawal AA. Evolution, current status and advances in application of platelet concentrate in periodontics and implantology. World J Clin Cases. 2017 May 16;5(5):159-171.Pubmed PMID:28560233.

[4]. Choukroun J, Diss A, Simonpieri A, Girard MO, Schoeffler C, Dohan SL, et al. Platelet-rich fibrin (PRF): a second-generation platelet concentrate. Part IV: clinical effects on tissue healing. Oral Surg Oral Med Oral Pathol Oral Radiol Endod2006.101:e56-e60.Pubmed PMID:16504852.

[5]. Dohan DM, Choukroun J, Diss A, Dohan SL, Dohan AJ, Mouhyi J, et al. Platelet-rich fibrin (PRF): a second-generation platelet concentrate. Part I: technological concepts and evolution. Oral Surg Oral Med Oral Pathol Oral Radiol Endod. 2006 Mar 1;101(3):e37-44.Pubmed PMID:16504849.

[6]. Ghanaati S, Booms P, Orlowska A, Kubesch A, Lorenz J, Rutkowski J, et al. Advanced platelet-rich fibrin: a new concept for cell-based tissue engineering by means of inflammatory cells. J Oral Implantol.. 2014Dec;40(6):679-89. Pubmed PMID:24945603.

[7]. Kobayashi E, Flückiger L, Fujioka-Kobayashi M, Sawada K, Sculean A, Schaller B, et al.Comparative release of growth factors from PRP, PRF, and advanced-PRF. Clin Oral Investig.2016 Dec 1;20(9):2353-60.Pubmed PMID:26809431.

[8]. Fujioka-Kobayashi M, Miron RJ, Hernandez M, Kandalam U, Zhang Y, Choukroun J.Optimized platelet-rich fibrin with the low-speed concept: growth factor release, biocompatibility, and cellular response. J Periodontol..2017 Jan 1;88(1):112-21.Pubmed PMID:27587367.

[9]. Dohan Ehrenfest D, Bielecki T, Mishra A, Borzini P, Inchingolo F, Sammartino $G$, et al. In search of a consensus terminology in the field of platelet concentrates for surgical use: platelet-rich plasma (PRP), plateletrich fibrin (PRF), fibrin gel polymerization and leukocytes. Curr Pharm Biotechnolx.2017Jun 1;13(7):1131-7.Pubmed PMID:21740379.

[10]. Bagdadi K, Kubesch A, Yu X, Al-Maawi S, Orlowska A, Dias A, et al. Reduction of relative centrifugal forces increases growth factor release within solid platelet-rich-fibrin (PRF)-based matrices: a proof of concept of LSCC (low speed centrifugation concept). Eur J Trauma Emerg Surg.. x 2017 Mar:1-3. Pubmed PMID:28324162.

[11]. Bainbridge P. Wound healing and the role of fibroblasts. J Wound Care. 2013 Aug;22(8):407-8, 410-12. Pubmed PMID: 23924840. 
[12]. Mosmann T.Rapid colorimetric assay for cellular growth and survival: application to proliferation and cytotoxicity assays. J Immunol Methods. 1983. Dec 16;65(1-2):55-63.Pubmed PMID:6606682.

[13]. Eppley BL, Pietrzak WS, Blanton M. Platelet-rich plasma: a review of biology and applications in plastic surgery. Plast Reconstr Surg. 2006 Nov 1;118(6):147e-59e.Pubmed PMID:17051095.

[14]. Almutairi AS.Platelet Rich Fibrin in Periodontal Practice, Review. International Journal. 2017; 5(5):132-6.

[15]. Prakash S, Thakur A. Platelet concentrates: past, present and future. J Maxillofac Oral Surg. X 2017 Mar;10(1):45-9. Pubmed PMID:22379320.

[16]. Maniyar N, Sarode GS, Sarode SC, Shah J.Platelet-Rich fibrin: A "wonder material” in advanced surgical dentistry. Medical Journal of Dr. DY Patil Vidyapeeth. 2017 Jul 1;11(4):287.

[17]. Meidyawati R, Suprastiwi E. The Ability of Lysate-PRF Induces Proliferation of Fibroblast Cells in Endodontic Regenerative Therapy. Open Journal of Stomatology. 2018 May 9;8(5):182-7.

[18]. Vahabi S, Vaziri S, Torshabi M, Rezaei Esfahrood Z. Effects of Plasma Rich in Growth Factors and Platelet-Rich Fibrin on Proliferation and Viability of Human Gingival Fibroblasts. J Dent (Tehran). 2015 Jul;12(7):504-12. Pubmed PMID: 26877740.

[19]. Weibrich G, Kleis WK, Hafner G, Hitzler WE.Growth factor levels in platelet-rich plasma and correlations with donor age, sex, and platelet count. J Craniomaxillofac Surg.2002 Apr;30(2):97-102.Pubmed PMID: 12069512.

[20]. Italiano Jr JE, Richardson JL, Patel-Hett S, Battinelli E, Zaslavsky A, Short $S$, et al.Angiogenesis is regulated by a novel mechanism: pro-and antiangiogenic proteins are organized into separate platelet $\alpha$ granules and differentially released. Blood. 2008 Feb 1;111(3):1227-33.PubmedPMID:17962514.

[21]. Dohan Ehrenfest DM, Diss A, Odin G, Doglioli P, Hippolyte MP, Charrier JB.In vitro effects of Choukroun's PRF (platelet-rich fibrin) on human gingival fibroblasts, dermal prekeratinocytes, preadipocytes, and maxillofacial osteoblasts in primary cultures. Oral Surg Oral Med Oral Pathol Oral Radiol Endod. 2009 Sep;108(3):341-52.Pubmed PMID: 19589702. 